\title{
Building research capacity in Malawian nursing education-A key to development and change
}

\author{
Bodil Tveit ${ }^{* 1}$, Eva Merethe Solum², Modesta Simango ${ }^{3}$ \\ ${ }^{1}$ Institute for Nursing and Health, Diakonhjemmet University College, Oslo, Norway \\ ${ }^{2}$ Faculty of Health Sciences, Department of Nursing Sciences, Buskerud and Vestfold University College, Norway \\ ${ }^{3}$ Norwegian Church Aid, Lilongwe, Malawi
}

Received: May 22, 2015

DOI: $10.5430 /$ jnep.v5n10p1
Accepted: June 29, 2015

Online Published: July 2, 2015

\begin{abstract}
Background: This article presents a study on a research capacity building project developed and implemented with 22 nurse educators in Malawi. The aim of the capacity building was to develop knowledge of and initiate research activities in and on nursing education in Malawi. The project was part of a long-term partnership between Norwegian and Malawian nurse educators which has run from 2005 to 2015.

Methods: An action research design comprised of three cycles, each which built on the other, was adopted. Participant observation, evaluations by participants, and reviews of participants' research work in progress provided data to assess the impact and challenges of the interventions, and make necessary adjustments.

Results: The results indicate that encouraging research on nursing education focused on locally defined problems is a fruitful and motivating way to improve teachers' competence. Participants found the intervention to be highly relevant to their work. They appreciated the cyclic approach and the alternation among input lectures, guided group work, and fieldwork. Participants valued the opportunity to analyze and discuss their own experiences in the light of relevant international research. They found the absence of existing research on nursing education in Malawi a motivation to continue researching.

Conclusions: Research capacity building for nurse educators through a participatory approach which addresses locally perceived problems can play an important role in the development of nursing education and practice. Increased collaboration among colleges and the creation of local professional learning communities are potential spin-off outcomes of this approach.
\end{abstract}

Key Words: Nursing education, Research, Capacity building, Critical thinking, Information literacy

\section{INTRODUCTION}

Important features of today's global health care field are the enormous increase in knowledge and the growing demand for research to underpin and develop practice. In high-income countries, these developments have emerged gradually over several decades and, step by step, have transformed practices and ways of thinking. ${ }^{[1]}$ However, in Malawi and many other low-income countries, the same processes started later and have been hindered by various factors, including difficulty accessing research-based information, ${ }^{[2,3]}$ a lack of resources, and the absence of a culture of research. ${ }^{[4-6]}$ Recently, access to research-based information has been improved dramatically in low-income countries, and most higher education institutions, including nursing colleges, have access to the Internet and important health research and scientific information in full-text articles. ${ }^{[7,8]}$

\footnotetext{
*Correspondence: Bodil Tveit; Email: tveit@ diakonhjemmet.no; Address: Institute for Nursing and Health, Diakonhjemmet University College, Oslo, Norway. 
Access to the Internet and updated information presents new opportunities but does not necessarily lead to change and development. The lack of a culture of research poses the risk that valuable research-based knowledge will be misinterpreted or not used at all. ${ }^{[7]}$ Another challenge is that most existing research has been conducted in western countries and is not always relevant to different contexts. The need for research capacity building in developing countries, therefore, is clear. ${ }^{[9]}$

Many scholars emphasize the central position of the nurse educator as an important facilitator of the improvement of health care systems. As implementers of innovation and change, teachers are critical to the success of all efforts to improve education. ${ }^{[10-12]}$ Consequently, the emphasis on teachers' learning has been increasing. In this article, we present ideas and results from a research capacity building project conducted with nurse teachers working in Malawian nursing colleges. The project was a multi-cycle intervention developed and implemented by a team of facilitators consisting of two Malawian and two Norwegian nurse educators and researchers.

\section{Background}

The training is part of a larger development project called the Improved Health Training Programme in Malawian Nursing Colleges, which was launched in 2005 with the overall goal to contribute to the improvement of nursing and midwifery services in Malawi. Norwegian Church Aid (NCA) and the Christian Health Association of Malawi (CHAM) initiated a strategic partnership involving fourteen Malawian nursing colleges and six Norwegian nursing colleges. As well, nurses' organizations in both countries have partnered in the implementation of the project. The project, which has run from 2005 to 2015, consists of two main parts: 1) developing infrastructure for the CHAM colleges, including classrooms, hostels, and skills labs; and 2) building the capacity of the nursing colleges to educate more qualified nurses. The capacity building component involves a multifaceted approach, concentrating on the training of tutors to meet the needs identified by the Malawian partners. The focus has been on the following themes: teaching and learning methods, curriculum development, clinical teaching in practice and skills labs, ethos and professionalism, including an emphasis on human rights and gender. The project has also secured library resources and teaching materials and strengthened resource management at the colleges. Since 2011, a focus on promoting research-based education has been undertaken.

The close connection between education and research has been emphasized in numerous works in recent decades and underlines the significant role that research is expected to play in modern higher education. ${ }^{[13,14]}$ Three often mentioned arguments are the following: 1) Research-based education enhances critical thinking and reflection, which are prerequisites to and essential components of professional accountability and quality and should be achieved by all students by completion of all types of professional education programs. ${ }^{[15]}$ 2) Research is closely linked to creative thinking and innovation. Professionals working in a society undergoing rapid change must be able to practice creative thinking and innovative attitudes in order to understand, participate in, and initiate change processes and take responsibility for lifelong learning. ${ }^{[11,16]} 3$ ) Scientific thinking is a fundamental social value and a prerequisite for democracy and confidence in the professions and social institutions. ${ }^{[5]}$

These arguments are also central to discussions in health care education and nursing. ${ }^{[16,17]}$ Frenk et al. describe the trends in the education of health professionals for a new century as a paradigmatic shift, in which more traditional views on education as the transmission of knowledge (informative) and socialization (formative), are being complemented by a new vision of educating enlightened change agents (transformative). ${ }^{[17]}$ Searching, analyzing, and synthesizing information in decision-making and problem solving are central elements of transformative learning. Education should be a driving force in the development of active, reflective, critical professionals who can use research-based knowledge in professional practice. ${ }^{[17]}$

Healey and Jenkins ${ }^{[14]}$ argue that the best way to learn how to use research is to participate actively in the research process. When people understand how research-based knowledge is produced, they more easily understand the implications of scientific thinking, develop a more critical attitude toward knowledge, and become more capable of distinguishing between relevant and less relevant knowledge.

The idea of addressing research as a theme in capacity building was suggested by the Malawian partners who recognized the need for such training. An initial proposal for a training program was developed based on an idea from the Canadian International Development Research Centre. ${ }^{[18]}$ The proposal was presented and approved by the Malawian partner colleges' management, CHAM, the Nurses and Midwives Council of Malawi (NMCM), and the Ministry of Health at a national stakeholders meeting for the Improved Health Training Programme in Malawian Nursing Colleges in Lilongwe in June 2010.

The overall aim of the intervention was to develop knowledge of and initiate research activities in and on nursing and midwife education in Malawi. Within this overarching goal were embedded three objectives: 1) increase teachers' ca- 
pacity to identify problems and critically analyze their own experiences and practices; 2) improve participants' information literacy through training in how to search for literature relevant to their problems and themes; and 3) encourage participants' ability to initiate changes based on their findings and results.

\section{MeTHODS}

An action research-inspired design was adopted to study the implementation and outcomes of the research capacity building process. Action research is a reflective method which focuses on participation, impact, and change related to a specific action or process. ${ }^{[19,20]}$ Action research can be described as a succession of cycles which each include planning, action, and evaluation. ${ }^{[21]}$ Action research is also characterized by the ongoing, continuous and reflexive tracking of the evolution of changes using the various perspectives of those involved. ${ }^{[22]}$

This intervention consisted of three cycles, which each built on the other and involved different actions to develop the infrastructure and processes for research capacity building in Malawian nursing and midwifery colleges. Throughout the project, participant observation, evaluations by participants, and reviews of participants' research work in progress provided data to assess and reflect on the impact and of the implementation and make necessary adjustments. The third cycle included the dissemination of the results from the research project.

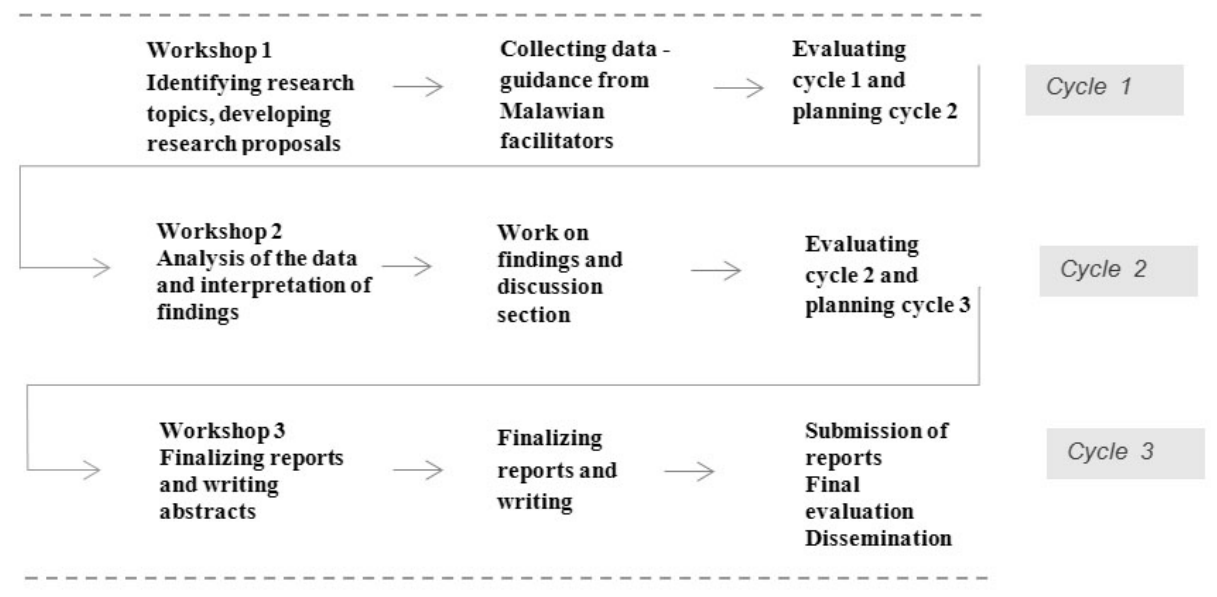

Figure 1. Intervention overview

\subsection{Participants}

Twenty-two tutors, of whom the majority held bachelor's degrees, participated in the research capacity building project. The participants represented 11 Malawian colleges offering registered nurse/midwife programs, a four-year degree course, or nurse-midwife-technician programs, a three-year diploma course. None of the participants had any significant research experience, except for theoretical training during their college education. Each college was encouraged to send two participants, and the importance of doing so for continuity and mutual support was stressed in the invitation. The importance of teamwork was also emphasized because much of the work was conducted at the colleges in between the three workshops, alongside participants' regular duties as teachers.

\subsection{Ethical issues}

Approval for the project was obtained from the NMCM, CHAM, and all the involved colleges in Malawi. Ethical aspects had a significant role in the project because it involved participants carrying out research projects in relation to their own work as college teachers. Specific ethical issues were raised several times during the process include the possible conflicts of being insiders with multiple roles, relations, and engagements within the context of research. ${ }^{[4]}$ From the perspective of practitioners' research and inquiry, the researcher's insider status is an asset which should be exploited because of the unique insights and the longitudinal viewpoint the researcher brings to the topic studied. ${ }^{[11]}$ However, it was also important to ensure that ethical issues, such as informed consent, confidentiality, accuracy, and thoroughness, were attended to throughout the process and that possibly sensitive information was treated with care.

\section{RESULTS, INTERVENTIONS, AND REFLEC- TIONS}

\subsection{Cycle 1}

The first cycle began with a nine-day workshop, with the expected outcome that groups of participants would make 
their own research proposals. The workshop started with a brief introduction to research and how to write research proposals. Then, in a group work session, participants were guided to think of research themes using the nominal group technique, a structured method for group brainstorming that encourages all participants to make contributions. ${ }^{[23]}$ The process resulted in an agreement on eight topics which addressed four central areas of nursing education: classroom learning, clinical learning, management and staff issues, and high failure rates on examinations.

Table 1. Research topics

\begin{tabular}{lll}
\hline Topic area & No. & Title \\
\hline $\begin{array}{l}\text { Classroom learning } \\
\text { High failure rates in } \\
\text { examinations }\end{array}$ & 1 & $\begin{array}{l}\text { Teaching methods that promote effective classroom learning in Malawian nursing and } \\
\text { midwives training institutions }\end{array}$ \\
\cline { 2 - 3 } & 2 & High failure rate of students in examinations in colleges of nursing in Malawi \\
\cline { 2 - 3 } \begin{tabular}{l} 
Clinical learning \\
\cline { 2 - 3 }
\end{tabular} & \begin{tabular}{ll} 
Factors leading to high failure rates of nursing students in licensure examinations \\
\cline { 2 - 3 }
\end{tabular} & $\begin{array}{l}\text { Factors that affect the acquisitions of psychomotor competencies in skills in the clinical area by } \\
\text { student nurses and midwifes in CHAM nursing colleges }\end{array}$ \\
\cline { 2 - 3 } Management/staff & 7 & $\begin{array}{l}\text { Knowledge attitudes and practice in the use of nursing process by clinical nurses in hospitals in } \\
\text { the southern region of Malawian hospitals }\end{array}$ \\
\hline
\end{tabular}

The workshop continued with short introductions to various relevant themes, such as writing problem statements, developing aims and objectives, conducting literature searches, and selecting data collection tools. All the introductions were followed by practical sessions in which participants worked with their groups on their proposals and by plenaries in which the groups presented their ideas and received feedback. The practical sessions included visiting the library and searching for literature under the guidance of a librarian. The data collection tools developed by the various groups were presented in a plenary role-play session. On the last day of the workshop, the participants finalized and submitted their proposals.

Over the next five months, the same groups of participants set out to collect data as specified in their proposals. The groups sought and obtained permission from the involved institutions to conduct research. Guided by the facilitators, the groups refined their research problems and objectives and ensured that the quality of the data collection tools was adequate before starting data collection. Before the second workshop, participants were responsible for completing data collection according to their plans and producing a verbatim transcription of the data.

\section{Reflection: Evaluation of Cycle 1}

The use of the nominal group technique process to select the research topics proved to be fruitful. At first, quite a few participants were hesitant to consider problems they had experienced in their college context and work as teachers.
However, very engaged discussions in the groups took place. The process of participants selecting themes from their own work context was crucial and gave them a sense of ownership in the project that many found motivating. The selected topics covered many central areas, but the most urgent theme at the time of the workshop was the high failure rate on the national exam that year. Several groups decided to develop research proposals to investigate the reasons for and causes of the failure rate. The alteration between input lectures, group work, and plenary sessions in the workshop worked well and created a dynamic atmosphere in the groups, especially given the limited time for each sequence. Participants seemed to appreciate the input lectures and the close connection between input and group work. In the evaluation, they made such comments as: "I have learned a lot," "[My] expectations [were] met through the participatory approach [the] facilitators used," and "This workshop has enabled me to look for researchable areas in nursing education that can improve the nursing profession." The teachers perceived the focus of the workshop as highly relevant to their work as college teachers: "I have increased my knowledge and skills, which will assist me in evidence-based teaching.” Participants evaluated the group work as very good, especially the opportunity to share ideas and knowledge.

Participants expressed high motivation to continue working on the project after the workshop. Many exhibited eagerness to commence data collection. Despite high motivation, many participants encountered challenges in the data collection process. Some had difficulty finding suitable or eligible sub- 
jects for their studies. Others felt that the time allocated for data collection was too short to do a good job with the exercise because it came on top of all their regular tasks as teachers. Problems in the group process were also reported and observed. The experience from cycle 1 emphasizes the need for supervision and close follow-up.

\subsection{Cycle 2}

Cycle 2 started with a five-day workshop, with the main aim to make the participants capable of analyzing and interpreting the data and findings of their projects. The facilitator group met before the workshop to adapt and modify the plans for the workshop based on the experiences from Cycle 1.

The workshop began a short plenary session to discuss the data collection process and the problems encountered by the groups. Despite these challenges, participants managed to do a considerable amount of work, and all brought transcribed material to the second workshop. The size and quality of the material, though, varied. The plenary session was followed by a short introduction to the process of analyzing qualitative data and by group work on data analysis to identify meaning units and code and categorize the data. The group work was interrupted occasionally by shorter plenary sessions to discuss difficulties, present ideas, and give input lectures on the analysis process, such as ethical aspects of the research process and the criteria for valid and trustworthy research. Participants also used a college library and received guidance in the literature search for their studies. On the last day of the workshop, participants were introduced to principles and elements of report writing and were guided in developing their own report outlines.

In the following months, participants continued the work they started during the workshop. Before the follow-up visits, participants were expected to analyze all their transcripts and refine their report outlines. Before the third workshop, participants were asked to develop a draft of the introduction, background, literature review, methodology, and findings sections of the report. Some groups realized that they needed more data when they started writing the findings section and decided to conduct more interviews. These groups had to work hard to catch up with the others. The facilitators conducted planned follow-up visits at all colleges between the second and third workshops.

\section{Reflection: Evaluation of Cycle 2}

In this stage of the process, it was important to work closely with the groups. Some groups expressed fatigue and seemed discouraged, and the facilitators had the important, necessary role to encourage and inspire the groups and reassure them that they could complete the work. Many participants

Published by Sciedu Press expressed their willingness to invest great effort in the assignment: "I am inspired to work up through the final stage. I want to see our document published." Most participants appreciated the importance of this opportunity to learn more about research and used it to keep up their spirits. The topics for the input lectures were issues considered relevant to this stage of the process. The following statements from participants' evaluation emphasize the significance they saw in the work: "As a nurse educator, it is a requirement for me to do research; otherwise, I will perish." "It will help me in understanding concepts in research and using them in teaching and conducting research." Progress in the work varied, and participants received advice according to their status. Some groups struggled and asked for extra supervision at their colleges. The facilitator group approved strengthening this part of the follow-up and considered it crucial for the groups to be able to accomplish their tasks.

\subsection{Cycle 3}

The third and last workshop lasted for five days and had the expected learning outcome that participants would be able to finalize their analyses, discuss the findings, and draw conclusions from their research projects in a valid and trustworthy way. Participants should also learn to write an abstract of their research report, develop recommendations based on their findings and discussions, see implications for future research, and reconsider ethical implications. Most groups arrived at the third workshop with drafts of the findings section of their reports. A few groups had written a full draft of the report.

The workshop began with a plenary session, in which all participants shared how far they had come. The groups were at very different stages. Most had started writing out their findings, and a few had started on the discussion section. The groups were in great need of individual guidance because they were at such different stages in their work. Consequently, the input lectures and plenaries were limited to the basic essentials, focusing on such themes as writing a discussion, formal requirements, and abstract writing. Participants were also encouraged to review the different sections of their reports, assess the need for more literature to support their discussions, and make a last visit to the library. At the end of the workshop, all the groups had gone over all the sections of the report and submitted their draft reports to their facilitators.

Participants left the last workshop with the task to complete their reports by a given deadline. While finalizing the reports, they were offered some guidance from their facilitators via e-mail. After being completed, the reports were disseminated at a national meeting in Malawi attended by all the 
colleges' leaders and stakeholders, such as the Ministry of Health, NMCM, and National Organization of Nurses and Midwives in Malawi. The presentations were highly appreciated and followed by interesting discussions on challenges and possible changes in nursing education in Malawi. All the colleges received a complete set of participants' reports for their libraries. In addition to presenting at the national stakeholder meeting, six of the eight groups submitted abstracts and were accepted to give paper presentations at the international conference Nursing Education in Africa-Changes and Challenges held in Lilongwe in November 2012.

\section{Reflection: Final evaluation}

At the end of the last workshop, participants were asked to evaluate their learning outcomes throughout the training process. The overall impression from the evaluation was that participants were very satisfied with the outcomes of the workshops and the training program: "The atmosphere of learning was conducive and made me enjoy every activity of the training!" Many participants stated that the training was highly relevant to their work as teachers. Participants saw as important the ability to teach better and use research in their teaching, and they found it helpful to access updated information related to the study program. Some participants pointed to the hard work they had done and the necessity of determination and commitment in research. Others mentioned the importance of learning to work together and share in groups within and across colleges. Quite a few emphasized another highly important learning outcome: their increased ability to investigate and assess problems in their work as teachers. Considering researchable topics related to education was new to them. The following statement sums up how participants perceived the relevance of the training: "It is relevant because it has helped me to realize our environment much better. I have realized that some of the problems that colleges are facing have solutions; they just need people to come up with those solutions."

All participants stated that they were very eager and highly motivated to disseminate their results. While appreciating their outcomes and achievements, many participants understood the complexity of research and the need to continue developing their skills as researchers: "I should be given feedback in order to see where I need improvement because I am still in the learning process." Some participants were inspired by the possibility of disseminating the findings to important stakeholders. Others were eager to see the results from their work in the college setting and any useful developments that emerged from their work: "I am really motivated to see that the work has been finalized and disseminated so that other people can benefit from this because I know that this is good work and has revealed some issues which people never realized." When asked if they had plans for further research, quite a few participants stated that they did. Some wanted to continue onto a master's program if they had the opportunity and do research on either clinical topics or themes related to education. A major outcome was that, after the training, participants felt more capable of identifying relevant topics for master's theses.

The quality of the final reports varied. The overall impression was that the research had revealed interesting and sometimes unexpected results. For example, the groups that investigated the high failure rate on the national exams started with clear assumptions about the causes, but the research brought out many nuances and possible explanations. The groups linked the high failure rate to a number of interrelated factors, including student motivation, college intake criteria, classroom and clinical teaching methodologies, learning environments, and the relationship between the teachers and students. The literature reviews by all the groups revealed that much research has been done elsewhere in the world on related themes. Participants realized that experiences from other contexts could provide important contributions to the understanding of problems in nursing education in Malawi. However, they also found that almost no research on nursing education has been undertaken in Malawi.

\section{Discussion}

A central purpose of the training was to increase teachers' capacity to critically analyze their experiences and practices. Cultivating a questioning approach to both theory and practice is essential to developing professional quality and improving nursing education and practice. ${ }^{[15]}$ As described, participants were encouraged to think of their own research themes related to education and their work as teachers. In our experience, this was a key element in the success and relevance of the intervention, as also described by other authors. ${ }^{[2,24,25]}$ The selected research topics were all perceived as central to participants' daily work in the colleges. They understood the importance of investigating a problem thoroughly, instead of immediately jumping to answers and solutions. By systematically focusing on the selected theme, asking questions, exploring theory, and assessing previous research findings, participants initiated a process of critical thinking. The unique potential to create a meeting place for nurse educators from throughout Malawi and to encourage them to identify, investigate, share, and discuss mutual challenges was an additional advantage of the training. Participants' growing recognition of the need to join forces in order to develop Malawian nursing education is an important, intended result of the intervention. Several researchers have argued for the importance of developing research capacity in 
ways that enhance and facilitate collaboration. ${ }^{[1,3,26,27]}$

Before the workshops, many participants had little knowledge of how to search for and refer to research literature. A main purpose of the training was to improve participants' information literacy by facilitating training and practice in how to search for and use literature relevant to their problems and themes. This training was done in collaboration with the college librarians. Although it takes time to gain expertise in this field, participants stated that they felt much more competent after the research training, which could be of great help to them in their work as teachers. The self-directed learning approach of the training served a double purpose by modelling a teaching and learning methodology participants could use as teachers, in addition to stimulating lifelong learning and continuing education processes. ${ }^{[11]}$ When searching for literature, participants generated many interesting findings. One was that the difficulties they experienced had been described as problems elsewhere in the world. Sometimes, knowledge and experiences from quite distant environments contributed interesting perspectives. Another finding was the almost total absence of research on nursing education from African contexts. Many participants stated that they were extremely motivated when they realized that they were in a position to start investigating an almost unexplored area.

A third intended outcome was to support participants' ability to initiate changes based on their findings and results. Asking questions and critically discovering and discussing problems does not necessarily lead to coming up with new ideas and solutions. Many participants in the training seemed to be fixed in a common way of thinking in their environment. When asked to give recommendations based on the findings in their research, some quickly concluded that the lack of resources (money) is the cause of most problems, and hence, the solution is to obtain more funds. Although many challenges and problems are related to the lack of financial resources, the discoveries and findings of the research projects encouraged participants to rethink and look for other possible solutions and innovative ideas that could be implemented with the available resources and assets at their colleges. In the end, most groups produced more realistic, specific, and feasible recommendations.

\section{Conclusion}

This study suggests that research capacity building for nurse educators with a participatory approach which addresses locally perceived problems can play an important role in developing nursing education and practice. The process of questioning established truths, learning how to pose researchable questions, investigating practices, searching for research-based information, and deliberating possible solutions to locally experienced problems were central to the success of the intervention. The highly motivated participants in this project emphasized the relevance and usefulness of the approach. Increased collaboration between the colleges and the creation of local professional learning communities in nursing colleges are important, promising outcomes of the intervention. Based on all these aspects, the experiences from this training could hopefully inspire new, exciting research projects related to nursing education in Malawi and contribute to meeting the important challenge of developing nursing education and practice.

\section{CONFlicts OF InTEREST Disclosure}

The authors declare that there is no conflict of interest.

\section{REFERENCES}

[1] Segrott J, McIvor M, Green B. Challenges and strategies in developing nursing research capacity: a review of the literature. Int J Nurs Stud. 2006 Sep; 43(5): 637-51. PMid:16157338 http: //dx.doi.org/10.1016/j.ijnurstu.2005.07.011

[2] Marshall-Lucette S, Corbett K, Lartey N, et al. Developing locally based research capacity in Uganda. Int Nurs Rev. 2007; 54(3): 227-33. PMid:17685905 http://dx.doi.org/10.1111/j.146 6-7657.2007.00565.x

[3] Lansang MA, Dennis R. Building capacity in health research in the developing world. Bull WHO. 2004; 82(10): 764-70. PMid:15643798

[4] Green B, Segrott J, Hewitt J. Developing nursing and midwifery research capacity in a university department: case study. J Adv Nurs. 2006; 56(3): 302-13. PMid:17042809 http://dx.doi.org/10. $1111 / j .1365-2648.2006 .04022 . x$

[5] Edwards N, Webber J, Mill J, et al. Building capacity for nurse-led research. Int Nurs Rev (Internet). 2009; 56(1): 88-94. PMid:19239521 http://dx.doi.org/10.1111/j.1466-7657.2008.00683.x

[6] Ogundahunsi OAT, Vahedi M, Kamau EM, et al. Strengthening research capacity-TDR's evolving experience in low- and middle-income countries. PLoS Negl Trop Dis. 2015; 9(1): 1-6. PMid:25569232 http://dx.doi.org/10.1371/journal.pntd. 0003380

[7] Tveit B, Wasili R, Kollstrom ML, et al. Curriculum implementation in CHAM/NMT-colleges in Malawi. Lilongwe: Christian Health Association of Malawi/Norwegian Church Aid. 2009; 54. PMid:19643658

[8] Katikireddi SV. HINARI: bridging the global information divide. BMJ. 2004 May; 328(7449): 1190-3. PMid:15142931 http: //dx .doi.org/10.1136/bmj.328.7449.1190

[9] Lindo JLM, Holder-Nevins D, Dover RD, et al. Shaping the research experiences of graduate students using action research. Nurse Educ Today. 2013; 33(12): 1557-62. PMid:23395211 http://dx.doi.o $\mathrm{rg} / 10.1016 / \mathrm{j} \cdot \mathrm{nedt} .2013 .01 .004$ 
[10] Profetto-McGrath J, Smith KB, Hugo K, et al. Nurse educators' critical thinking dispositions and research utilization. Nurse Educ Pract. 2009; 9(3): 199-208. PMid:18701349 http://dx.doi.org/10. 1016/j.nepr.2008.06.003

[11] Cochran-Smith M, Lytle SL. Inquiry as stance: practitioners research for the next generation. New York: Teachers College Press; 2009. 401.

[12] Solum EM, Maluwa VM, Severinsson E. Ethical problems in practice as experienced by Malawian student nurses. Nurs Ethics. 2012; 19(1): 128-38. PMid:22140182 http://dx.doi.org/10.1177/0 969733011412106

[13] Barnett R, editor. Reshaping the university: new relationships between research, scholarship and teaching. New York: Society for Research into Higher Education \& Open University Press; 2005.

[14] Healey M, Jenkins A. Developing undergraduate research and inquiry. York: The Higher Education Academy; 2009. 156.

[15] Drennan J. Critical thinking as an outcome of a master's degree in nursing programme. J Adv Nurs. 2010; 66(2): 422-31. PMid:20423425 http://dx.doi.org/10.1111/j.1365-2648. 2009.05170.x

[16] Benner P. Educating nurses. San Francisco: Jossey-Bass; 2010. 260.

[17] Frenk J, Chen L, Bhutta ZA, et al. Health professionals for a new century: transforming education to strengthen health systems in an interdependent world. Lancet. 2010 Nov; 376(9756): 1923-58. http://dx.doi .org/10.1016/S0140-6736(10)61854-5

[18] Varkevisser CM, Pathmanathan I, Brownlee A. Designing and conducting health systems research projects. Ottawa: International Development Research Centre; 1995. PMid:8553438
[19] McNiff J, Whitehead AJ. Doing and writing action research. London: Sage Publications Ltd; 2009. 201.

[20] Williamson GRB, Bellman L, Webster J. Action research in nursing and healthcare. London: Sage Publications Ltd; 2012. 247. http://dx.doi.org/10.4135/9781446289112

[21] Coghlan D, Casey M. Action research from the inside: issues and challenges in doing action research in your own hospital. J Adv Nurs. 2001; 35(5): 674-82. PMid:11529969 http://dx.doi.org/10. 1046/j.1365-2648.2001.01899.x

[22] Kemmis S, McTaggart R. Participatory action research. In: Denzin N, Lincoln Y, editors. Handbook of qualitative research. London: Sage; 2000. 567-606.

[23] ASQ: nominal group technique (NGT). (cited 2015 May 6). Available from: http://asq.org/learn-about-quality/idea-c reation-tools/overview/nominal-group.html

[24] Sitthi-Amorn C, Somrongthong R. Strengthening health research capacity in developing countries: a critical element for achieving health equity. BMJ. 2000 Sep; 321(7264): 813-7. PMid:11009525 http://dx.doi.org/10.1136/bmj.321.7264.813

[25] Nchinda TC. Research capacity strengthening in the South. Soc Sci Med. 2002 Jul; 54(11): 1699-711. http://dx. doi.org/10.1016 /S0277-9536 (01) 00338-0

[26] Priest H, Roberts P, Higginson G, et al. Understanding the research process in nursing. Nurs Stand. 2006 Oct; 21(1): 39-42. PMid:17016986 http://dx.doi.org/10.7748/ns2006.09.21. 1.39.c6405

[27] Nchinda TC. Research capacity development for CVD prevention: the role of partnerships. Ethn Dis. 2003 Sep; 13(2 Suppl 2): S40-4. PMid:13677412 